\title{
Multiple Remote Cutaneous Metastases from Male Breast Carcinoma- Cytodiagnosis of a Case
}

\section{Shelke VN*, Khandekar SL, Lodha ND and Raut WK}

Department of Pathology, S. V. N. Government Medical College, Waghapur road, Yavatmal, Maharashtra-445001, India

\section{Introduction}

Fine Needle Aspiration Cytology (FNAC) is well established procedure in the diagnosis and management of breast lesions in women. However, it is underutilized procedure for the management of male breast lesions. Gynecomastia is the most common male breast disorder. The incidence of breast carcinoma in men is low, accounting for less than $1 \%$ of all breast cancers and less than $1.5 \%$ of all malignancies in men [1-3]. Multiple distant cutaneous metastases from male breast carcinoma are rare finding. In the English language literature few references are present about this subject, and very few are reported on cytology $[4,5]$. We herein present a case of multiple remote papulonodular cutaneous metastases from breast carcinoma in a 47-year-old man.

\section{Case History}

A 47-year-old man (residing at Gangaon Sakur, Arni Taluka, Yavatmal District, Maharashtra State, India), farmer and fisher by profession, presented with lump in the left breast of one-year duration along with multiple swellings on the skin of four months duration. He had no other complaint and denied any family history of breast cancer. He was chronic alcoholic and bidi-smoker. Preoperative liver and renal function tests were within normal ranges. Dietary history revealed him to be a vegetarian as well non-vegetarian. Patient was non-diabetic and non-hypertensive. No history of radiation therapy to the chest or hormone therapy was elicited. The results of a physical examination showed a well-developed and well-nourished man. There was a $3-\mathrm{cm}$, palpable subareolar nodular mass in the left breast with nipple retraction and puckering of the overlying skin. Tenderness was present. No discharge was evident. Axillary lymph nodes were not palpable. The right breast was unremarkable. Examination also revealed multiple non-ulcerated, papulonodular lesions over the skin of chest, abdomen, extremities and scalp (Figure 1). The papulonodular lesions were of varying sizes ranging from 0.3 to $1.4 \mathrm{~cm}$ and were firm to hard in consistency. Fine needle aspiration was performed from

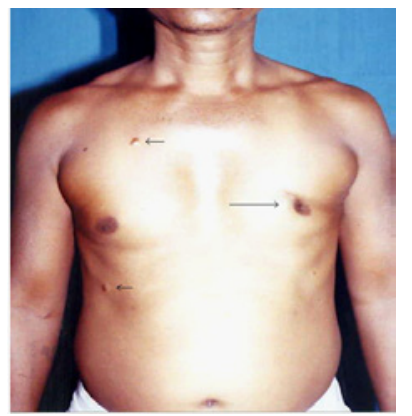

Figure 1: Clinical photograph of the patient showing lump in left breast with nipple retraction and puckering of overlying skin (long arrow) and two papulonodular lesions on trunk (short arrows).

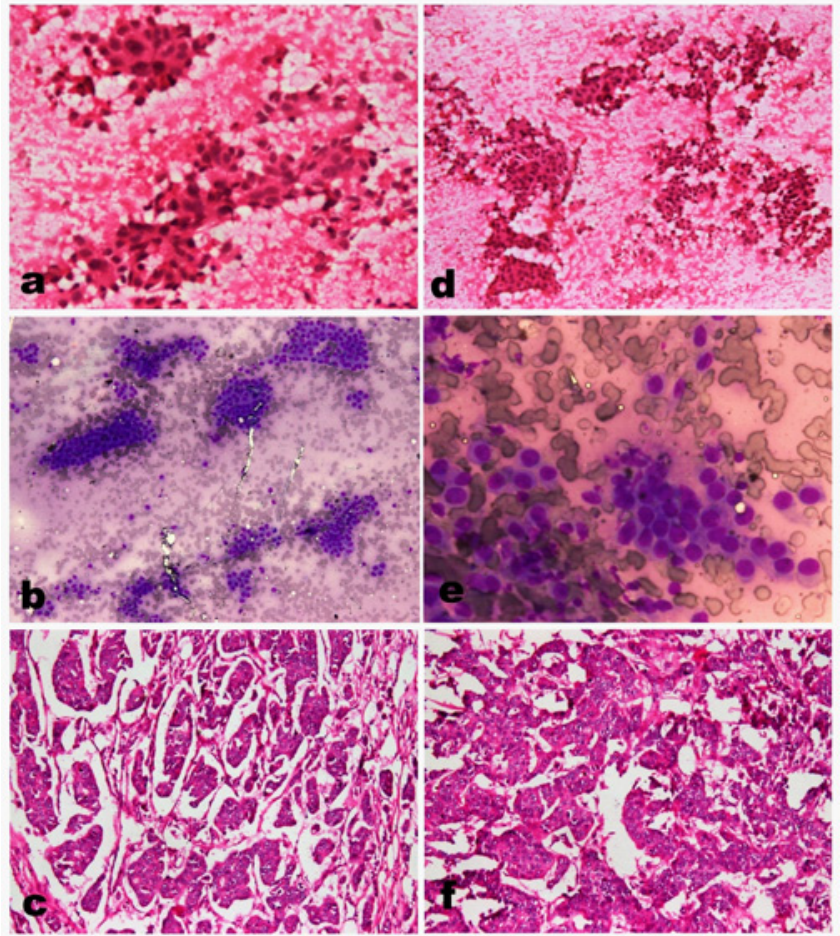

a, b, d and e - Highly cellular FNAC smears showing scattered and poorly cohesive clusters of epithelial cells.

$\mathrm{C}$ and $\mathrm{f}$ - Sections showing typical features of ductal carcinoma not otherwise specified (NOS) in the form of tubules, cords and sheets of ductal epithelial cells. a, c, d, \& f - hematoxylin \& eosin stain,

b \& e - Leishman's stain; original magnifications, a: x200, b-d, f: x100, e: $x 400$

Figure 2: Cytopathology and histopathology of breast lesion (left panel - a, b, \& c) and that of skin nodule (right panel - d, e, \& f) displayed identical findings.

breast and one nodule each on the trunk and right forearm. Cytology findings were similar from all three sites. FNAC diagnosis was given as ductal carcinoma of breast with multiple cutaneous metastases. Histopathologic study of the resected breast specimen and nodule on right forearm confirmed the cytological diagnosis.

*Corresponding author: Department of Pathology, S. V. N. Government Medical College, Waghapur road, Yavatmal, Maharashtra-445001, India, Tel: 9120 26006250; Fax: 9120 26122669; E-mail: vijaynshelke@yahoo.com

Received June 11, 2012; Accepted July 14, 2012; Published July 16, 2012

Citation: Shelke VN, Khandekar SL, Lodha ND, Raut WK (2012) Multiple Remote Cutaneous Metastases from Male Breast Carcinoma- Cytodiagnosis of a Case. $J$ Cytol Histol 3:148. doi:10.4172/2157-7099.1000148

Copyright: ( 2012 Shelke VN, et al. This is an open-access article distributed under the terms of the Creative Commons Attribution License, which permits unrestricted use, distribution, and reproduction in any medium, provided the original author and source are credited. 


\section{Cytological Findings}

FNAC was performed from lump in the left breast and skin nodules on the trunk and forearm. FNAC yields from all three sites were highly cellular and showed similar cytological features. Smears were stained with hematoxylin \& eosin, and Leishman's stains. The highly cellular smears showed scattered and poorly cohesive clusters of epithelial cells. The cells were large round to oval in shape with high Nucleus-to-Cytoplasm (N/C) ratio. The enlarged nuclei were hyperchromatic pleomorphic with occasional prominent nucleolus. Singly scattered cells with intact cytoplasm were noted (Figures $2 a, 2 b$, $2 \mathrm{~d}$ and $2 \mathrm{e}$ ). Single bare nuclei of benign type were absent. Based on FNAC findings, diagnosis of ductal carcinoma of breast with multiple cutaneous metastatic deposits was made. The FNAC diagnosis was confirmed by histopathological study (Figures $2 \mathrm{c}$ and $2 \mathrm{f}$ ) of resected mastectomy specimen and nodule on a forearm.

\section{Discussion}

Male breast carcinomas have been associated with gynecomastia, liver cirrhosis, testicular trauma, testicular tumours, undescended testis, infertility, radiation therapy and hormonal (estrogen) therapy. Increased risk has also been observed with cases having history of breast tumours in first degree relatives and cases with genetic disorders such as Klinefelter's syndrome and Cowden's disease [6-8]. The occurrence of breast cancers in male has been related with the BRCA2 gene mutation and in some patients involves BRCA1 [9-11]. The patient from this report did not have any of the above obvious risk factor that could justify the high risk for breast carcinoma.

In males, the most common sources of metastatic tumour to the skin are lung, whereas in females, the breast is by far the most common source [12]. The most common sites for skin metastases are chest and abdomen, followed by head and neck; location in the extremities is rare. In most cases metastases are multiple and appear as firm nonulcerated nodules $[13,14]$. One recent meta-analytical study revealed $5.3 \%$ of overall incidence of cutaneous metastases and breast cancer as the most common tumour to metastasize to the skin [15].

The anterior chest wall is commonly involved by recurrences of carcinoma of the breast usually through lymphatic spread and direct invasion; although distant cutaneous metastases are uncommon $[6,14]$. A study of 724 patients with cutaneous metastases recorded 168 cases in the women with carcinoma of the breast (69\% of the total number of women in the series) and nine in men. In 20 of these there were single distant metastases; in three there were multiple metastases. In the remainder, only the chest wall was involved [16].

FNAC is now routinely used for the diagnosis and management of breast lesions in females. However it is still underutilised procedure for the male breast lesions. Probable reasons could be: one, breast masses in males are less frequent; second, gynecomastia in male may pose some problem and can be confused with carcinoma and this may affect the reliability of FNAC; third, unlike concerns in females, asymptomatic and non-palpable breast lesions in men remained unscreened. The technique is simple, quick, safe, acceptable and inexpensive and good results are attainable. Due to high diagnostic accuracy, FNAC should be routinely practiced as an important diagnostic tool in all male patients with breast lesions. FNAC may be also useful in investigating the site of a possible primary when cutaneous metastases are the first clinical manifestation $[17,18]$.

The reliability of Fine-Needle Aspiration Cytology (FNAC) of breast masses in males could be compromised by lack of experience because the incidence of breast carcinoma in men is much low compared with women and FNAC is not often used. In addition, FNAC of the more often encountered gynecomastia may lead to over diagnosis as it may result in an atypical cytologic diagnosis. The objective of performing FNAC is to select those lesions that need to be treated and to avoid unnecessary surgery in patients with benign lesions. Benign: malignant ratios observed in resected specimens from male breast lesions were 3.5:1 verses 19.8:1 with and without preoperative FNAC respectively [19]. Due to the good cytohistologic correlations in the group of malignant lesions, the calculated sensitivity and specificity for the malignant cases could be reached up to $100 \%$ [20,21].

This case is presented here in view of its extreme rarity and also to reemphasize the importance and utility of FNAC in the diagnosis and management of male breast lesions.

\section{References}

1. Fentiman IS, Fourquet A, Hortobagyi GN (2006) Male breast cancer. Lancet 367: 595-604

2. Rudlowski C (2008) Male breast cancer. Breast Care (Basel) 3: 183-189.

3. Gómez-Raposo C, Zambrana Tévar F, Sereno Moyano M, López Gómez M, Casado E (2010) Male breast cancer. Cancer Treat Rev 36: 451-457.

4. Karakuzu A, Koc M, Ozdemir S (2006) Multiple cutaneous metastases from male breast carcinoma. J Am Acad Dermatol 55: 1101-1102.

5. Ai-Ping F, Yue Q, Yan W (2007) A case report of remote cutaneous metastasis from male breast carcinoma. Int J Dermatol 46: 738-739.

6. Juan Rosai (2004) Rosai and Ackerman's Surgical Pathology, Volume 2. (9th Edn) Elsevier, Philadelphia.

7. Misra SP, Misra V, Dwivedi M (1996) Cancer of the breast in a male cirrhotic: is there an association between the two? Am J Gastroenterol 91: 380-382.

8. Ganly I, Taylor EW (1995) Breast cancer in a trans-sexual man receiving hormone replacement therapy. Br J Surg 82: 341.

9. Frank TS, Deffenbaugh AM, Reid JE, Hulick M, Ward BE, et al. (2002) Clinica characteristics of individuals with germline mutations in BRCA1 and BRCA2: analysis of 10,000 individuals. J Clin Oncol 20: 1480-1490.

10. Friedman LS, Gayther SA, Kurosaki T, Gordon D, Noble B, et al. (1997) Mutation analysis of BRCA1 and BRCA2 in a male breast cancer population. Am J Hum Genet 60: 313-319.

11. Haraldsson K, Loman N, Zhang QX, Johannsson O, Olsson H, et al. (1998) BRCA2 germ-line mutations are frequent in male breast cancer patients without a family history of the disease. Cancer Res 58: 1367-1371.

12. Lookingbill DP, Spangler N, Helm KF (1993) Cutaneous metastases in patients with metastatic carcinoma: a retrospective study of 4020 patients. J Am Acad Dermatol 29: 228-236.

13. Lookingbill DP, Spangler N, Sexton FM (1990) Skin involvement as the presenting sign of internal carcinoma. A retrospective study of 7316 cancer patients. J Am Acad Dermatol 22: 19-26.

14. Johnson WC (1997) Metastatic carcinoma of the skin. Incidence and dissemination. Lever's histopathology of the skin. (8thedn), Lippincott Raven Publishers: Philadelphia.

15. Krathen RA, Orengo IF, Rosen T (2003) Cutaneous metastasis: a metaanalysis of data. South Med J 96: 164-167.

16. Brownstein MH, Helwig EB (1972) Metastatic tumors of the skin. Cancer 29 1298-1307. 
Citation: Shelke VN, Khandekar SL, Lodha ND, Raut WK (2012) Multiple Remote Cutaneous Metastases from Male Breast Carcinoma- Cytodiagnosis of a Case. J Cytol Histol 3:148. doi:10.4172/2157-7099.1000148

Page 3 of 3

17. Karki S, Pathak R, Manandhar U, Koirala S (2011) Metastatic cutaneous and subcutaneous lesions: Analysis of cases diagnosed on fine needle aspiration cytology. Journal of Pathology of Nepal 1: 37-40.

18. Gupta RK, Naran S (1999) Fine needle aspiration cytology of cutaneous and subcutaneous metasttic deposits from epithelial malignancies. An analysis of 146 cases. Acta Cytol 43: 126-130.

19. Westenend PJ, Jobse C (2002) Evaluation of fine-needle aspiration cytology of breast masses in males. Cancer 96: 101-104.

20. Lilleng R, Paksoy N, Vural G, Langmark F, Hagmar B (1995) Assessment of fine needle aspiration cytology and histopathology for diagnosing male breast masses. Acta Cytol 39: 877-881.

21. Rosen DG, Laucirica R, Verstovsek G (2009) Fine needle aspiration of male breast lesions. Acta Cytol 53: 369-374. 